\title{
Refractive index control in bicomponent polymer films for integrated thermo-optical applications
}

\author{
Paulo Azevedo Soave \\ Ronaldo André Ferreira Dau \\ Universidade Federal do Rio Grande do Sul \\ (UFRGS) \\ Instituto de Física \\ Laboratório Laser e Óptica \\ Programa de Pós-Graduação em Microeletrônica \\ Av. Bento Gonçalves 9500 \\ Caixa Postal 15051 \\ Porto Alegre, RS 91501-970 \\ Brazil \\ E-mail: soave@ufrgs.br
}

\section{Márcia Regina Becker}

Universidade Federal do Rio Grande do Sul (UFRGS)

Laboratório de Materiais Poliméricos

Av. Bento Gonçalves 9500

Setor 4, Prédio 74

Sala 117, LAPOL

Porto Alegre, RS 91501-970

Brazil

\author{
Marcelo Barbalho Pereira \\ Flavio Horowitz \\ Universidade Federal do Rio Grande do Sul \\ (UFRGS) \\ Instituto de Física \\ Laboratório Laser e Óptica \\ Programa de Pós-Graduação em Microeletrônica \\ Av. Bento Gonçalves 9500 \\ Caixa Postal 15051 \\ Porto Alegre, RS 91501-970 \\ Brazil
}

\section{Introduction}

The thermo-optical effect is present in transparent materials, including organic thin films, semiconductors, and dielectric bulks, ${ }^{1}$ and has been used for integrated optical devices in the microelectronics industry. Particularly, the effect is characterized by the thermo-optical coefficient (TOC), which is related to refractive index behavior when temperature is modified.

From the Lorentz-Lorenz expression, ${ }^{2}$ the Prod'homme relation $^{3}$ can be obtained as:

$T O C=\frac{\mathrm{d} n}{\mathrm{~d} T}=\frac{\left(n^{2}-1\right)\left(n^{2}+2\right)}{6 n}(\Phi-\beta)$,

where $T$ is the temperature, $n$ is the refractive index, and $\Phi$ is the electronic polarizability. Already, the volumetric expansion coefficient $(\beta)$ is defined as:

0091-3286/2009/\$25.00 @ 2009 SPIE

\begin{abstract}
Optical properties of transparent polymer thin films, produced by spin-coating on silicon and constituted of polycarbonate (PC), poly(methyl methacrylate) (PMMA), and PC/PMMA, were investigated with regard to integrated thermo-optical (TO) device applications. Refractive index dependences on wavelength, temperature, and film composition trolled heater setup, in the ranges of 400 to $800 \mathrm{~nm}, 25$ to $85^{\circ} \mathrm{C}$ and 0 to 100 wt \% PC, respectively, with determination of Cauchy and Lorentz-Lorenz parameters. Within these intervals, thermomechanica compatibility and pronounced index contrast of around 0.12 between PC and PMMA, as well as their TO coefficients one order of magnitude higher than that of silica, allow convenient tailoring for specific TO requirements. In addition, wide-range fine-tuning of refractive index variation is found to be facilitated by the weak dependence of isothermal dispersion curves and TO coefficients on film composition. ( 2009 Society of Photo-Optical Instrumentation Engineers. [DOI: 10.1117/1.3275452]
\end{abstract}

Subject terms: poly(methyl methacrylate); polycarbonate; polymer; ellipsometry; thermo-optic.

Paper 090597R received Aug. 5, 2009; revised manuscript received Oct. 21, 2009; accepted for publication Oct. 22, 2009; published online Dec. 28, 2009. $\beta=-\frac{1}{\rho} \frac{\mathrm{d} \rho}{\mathrm{d} T}$,

where $\rho$ is the material density.

Due to its affinity to silicon technology, silica has been used as a material of choice in integrated thermo-optical devices. However, those devices present high fabrication costs, as well as high electrical consumption during operation. Furthermore, due to its low thermo-optic coefficient, the efficiency of refractive index modulation in silica is more than 10 times lower than that for polymers. ${ }^{4,5}$

In this context, pure polymers, polymeric composites, and hybrid organic/inorganic compounds have been studied as alternative materials to silica-based devices. ${ }^{6-8}$ Among these materials, polymer composites have more flexibility in terms of refractive index, which is achieved by adjustment of their composition. This advantage becomes interesting in stringent applications that require a specific refractive index value. 


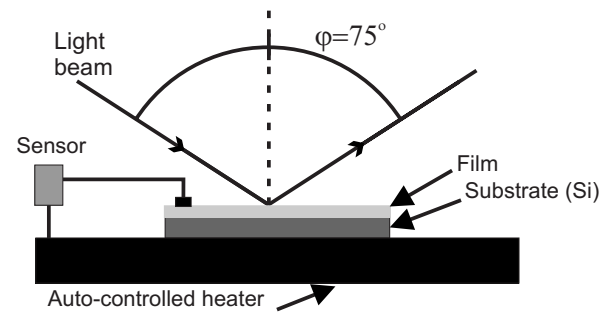

Fig. 1 Autocontrolled heater setup. The sample is placed over the heater during the ellipsometric measurement. Sample temperature is controlled with a sensor fixed on the film surface.

On the other hand, polymers are very often used in research and industry and are commercially available. In particular, Zhang et al. ${ }^{9}$ previously reported several TOC values of pure polymer films, altough not for their combinations, including polycarbonate $(\mathrm{PC})$ and poly $(\mathrm{m}-$ ethyl methacrylate) (PMMA). These two polymers have similar mechanical and thermal properties: density, thermal conductivity, thermal diffusivity, thermal expansion coefficient, and Young's modulus. ${ }^{10-12}$ Furthermore, their refractive index temperature dependences are well known. ${ }_{4,13}$

However, to our knowledge, studies of PC/PMMA film properties as a function of constituent concentration and temperature for thin films were not reported previously. This is the aim of this paper, which includes detailed film preparation and optical characterization procedures, with regard to compositional PC/PMMA tailoring of refractive indices for specific TO requirements. Last, dispersion curves and their corresponding thermo-optical coefficients of the prepared films in the 25 to $85^{\circ} \mathrm{C}$ temperature range will be presented.

\section{Experiment}

Films of PC/PMMA (PC from Bayer and PMMA from Aldrich) in concentrations of $20,40,50$, and $80 \mathrm{wt} \%$ of PC, as well as the PC and PMMA pure polymers, were prepared via solution blending at room temperature, using tetrahydrofuran (THF) as solvent. The polymer concentration was $4 \mathrm{wt} \%$ in solvent, and the solutions were filtered through a $0.2-\mu \mathrm{m}$ polytetrafluoroethylene (PTFE) micropore membrane. The solutions were used to prepare thin films on polished silicon substrates $(25 \mathrm{~mm} \times 25 \mathrm{~mm} \times 0.5 \mathrm{~mm})$ by the spin-coating process under saturated THF atmosphere. After deposition, the films were dried for complete removal of the solvent.

For measurement comparisons, all films were prepared with physical thicknesses between 300 and $600 \mathrm{~nm}$. This control was achieved by adjusting individually the spinner speed (2500 to $3000 \mathrm{rpm}$ ), for each film deposited, and confirmed by ex situ Ambios XP2 mechanical profilometer measurements.

To investigate sample thermo-optic response at different temperatures, a controlled heater device (temperature fluctuation of $\pm 1{ }^{\circ} \mathrm{C}$ ) was built (see Fig. 1) and integrated into a SOPRA GES-5E spectroscopic ellipsometer, allowing in situ measurements. The ellipsometer uses one rotating polarizer, one analysis polarizer (fixed), and the Hadamard method $^{14}$ to analyze the output polarization state of light and extract two components, $\sigma$ and $\tau$, for each wavelength $(\lambda)$ :

Table 1 Obtained Cauchy coefficients (A, B, and C) of pure polymer solutions and PC/PMMA at different temperatures.

\begin{tabular}{|c|c|c|c|c|c|c|c|c|c|}
\hline \multirow[b]{2}{*}{$\mathrm{T}\left({ }^{\circ} \mathrm{C}\right)$} & \multicolumn{3}{|c|}{ PMMA } & \multicolumn{3}{|c|}{ PC 40 wt \% } & \multicolumn{3}{|c|}{ PC 80 wt \% } \\
\hline & $A$ & $\mathrm{~B}\left(\times 10^{-3}\right)$ & $C\left(\times 10^{-4}\right)$ & A & $\mathrm{B}\left(\times 10^{-3}\right)$ & $C\left(\times 10^{-3}\right)$ & A & $\mathrm{B}\left(\times 10^{-3}\right)$ & $C\left(\times 10^{-4}\right)$ \\
\hline 25 & 1.479 & 5.48 & -1.72 & 1.542 & 2.21 & 0.49 & 1.585 & 6.59 & 3.40 \\
\hline 40 & 1.477 & 5.56 & -1.76 & 1.543 & 0.22 & 0.75 & 1.583 & 6.29 & 3.78 \\
\hline 55 & 1.474 & 5.89 & -2.23 & 1.544 & -1.14 & 0.92 & 1.581 & 5.91 & 4.27 \\
\hline 70 & 1.472 & 6.04 & -2.43 & 1.543 & -1.75 & 0.99 & 1.579 & 5.66 & 4.58 \\
\hline \multirow[t]{2}{*}{85} & 1.469 & 6.25 & -2.71 & 1.541 & -1.93 & 1.02 & 1.578 & 5.48 & 4.82 \\
\hline & \multicolumn{3}{|c|}{ PC 20 wt \% } & \multicolumn{3}{|c|}{ PC 50 wt \% } & \multicolumn{3}{|c|}{ PC } \\
\hline $\mathrm{T}\left({ }^{\circ} \mathrm{C}\right)$ & $A$ & $\mathrm{~B}\left(\times 10^{-4}\right)$ & $C\left(\times 10^{-4}\right)$ & A & $\mathrm{B}\left(\times 10^{-3}\right)$ & $C\left(\times 10^{-3}\right)$ & A & $\mathrm{B}\left(\times 10^{-3}\right)$ & $C\left(\times 10^{-4}\right)$ \\
\hline 25 & 1.518 & 8.34 & 6.16 & 1.576 & -5.05 & 1.68 & 1.597 & 3.96 & 8.57 \\
\hline 40 & 1.517 & 5.47 & 6.49 & 1.574 & -5.06 & 1.68 & 1.592 & 4.42 & 7.91 \\
\hline 55 & 1.515 & 4.04 & 6.64 & 1.571 & -4.54 & 1.61 & 1.590 & 4.31 & 7.99 \\
\hline 70 & 1.513 & 3.66 & 6.67 & 1.569 & -4.50 & 1.60 & 1.588 & 4.20 & 8.02 \\
\hline 85 & 1.511 & 6.55 & 6.27 & 1.567 & -4.11 & 1.54 & 1.585 & 4.52 & 7.53 \\
\hline
\end{tabular}




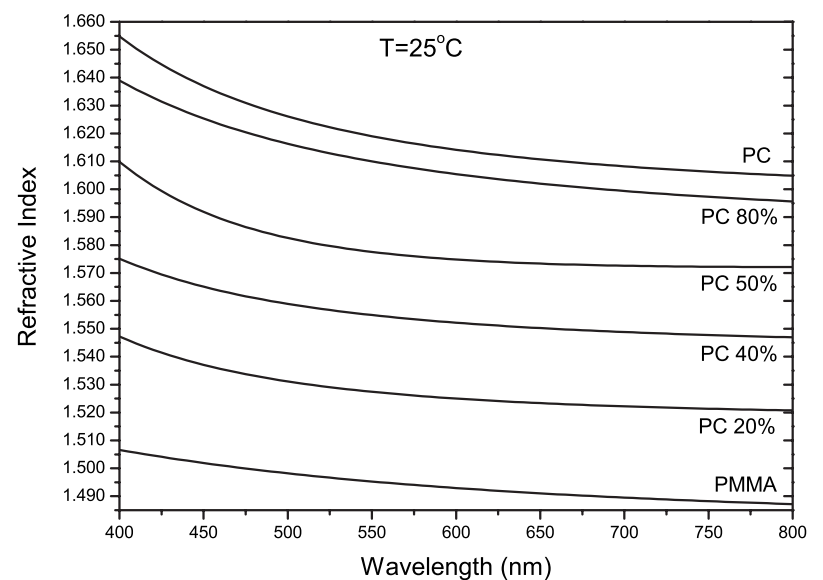

(a)

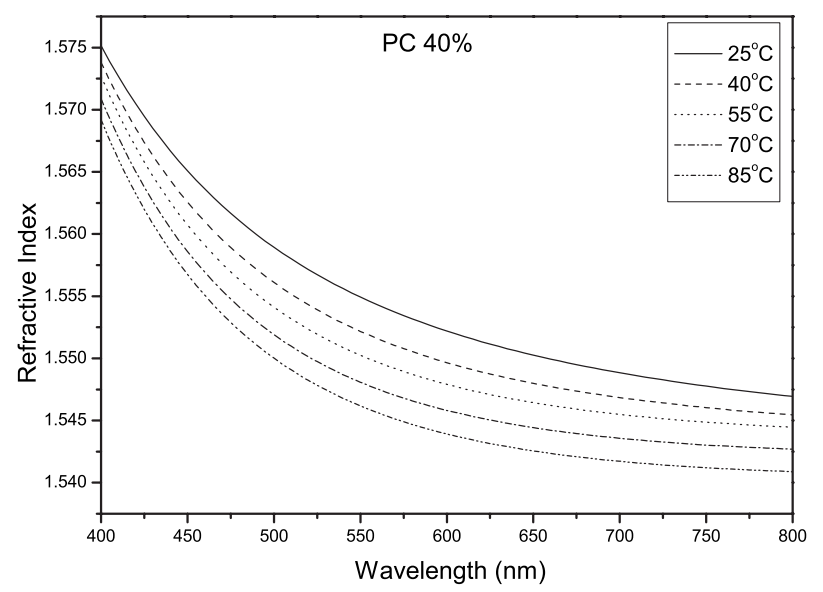

(b)

Fig. 2 (a) Dispersion curves at $25^{\circ} \mathrm{C}$ for pure polymers and $\mathrm{PC} /$ PMMA films, and (b) dispersion curves of PC 40 wt.\% film with PMMA for different temperatures. All dispersion curves were obtained by spectroscopic ellipsometry.

$\sigma=\frac{\tan ^{2} \psi-\tan ^{2} A^{\prime}}{\tan ^{2} \psi+\tan ^{2} A^{\prime}}$

and

$\tau=2 \cos \Delta \frac{\tan \psi \tan A^{\prime}}{\tan ^{2} \psi+\tan ^{2} A^{\prime}}$,

where $\tan \Psi$ and $\Delta$ are the amplitude ratio and phase shift difference, respectively, between values associated with the transverse magnetic (TM) and transverse electric (TE) polarization components of light (parallel and perpendicular to the plane of incidence, respectively), and $A^{\prime}$ is the angle between the transmission axis of the analysis polarizer and the light incidence plane. ${ }^{2}$

The resultant curves were used with the ellipsometer's analysis-modeling software to perform the curve fitting, assuming that the films have isotropic, dielectric, and homogeneous behavior, with the well-known Cauchy formula as refractive index dispersion function: ${ }^{2}$

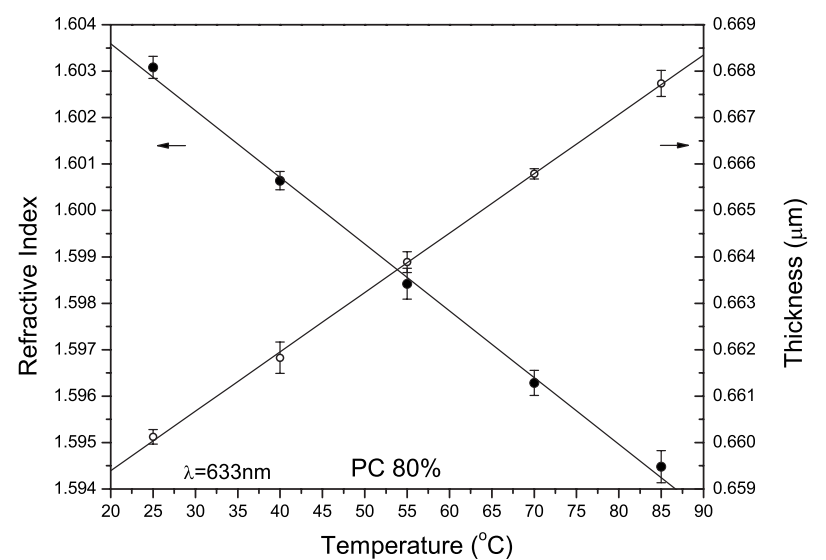

Fig. 3 Refractive index and physical thickness variation with standard deviation versus temperature for a pure PC film.

$n(\lambda)=A+\frac{B}{\lambda^{2}}+\frac{C}{\lambda^{4}}$,

where $A, B$, and $C$ are constants. As a result, film physical thicknesses $(h)$ and dispersion curves are obtained.

All measurements were performed using a light beam at an incident angle $(\varphi)$ of $75 \mathrm{deg}$, in the wavelength range of 400 to $800 \mathrm{~nm}$. To avoid phase transitions in the films, the measurements were performed at temperatures of 25,40 , 55,70 , and $85^{\circ} \mathrm{C}$, which are lower than the glass transition temperatures of PC and PMMA (both higher than $100{ }^{\circ} \mathrm{C}$ ). Furthermore, to avoid shifts in the refractive index values caused by film water adsorption, ${ }^{15}$ room relative humidity was controlled at levels of 40 to $50 \%$.

\section{Results and Discussion}

A total of nine measurements were performed with the spectroscopic ellipsometer for each sample, taken during a down-up-down temperature cycle. From these measurements, film physical thicknesses were obtained and dispersion curves calculated using the Cauchy coefficients (see Table 1).

The dispersion curves obtained for PC, PMMA, and PC/ PMMA at temperature $25^{\circ} \mathrm{C}$ are presented in Fig. 2(a). As can be seen in the figure, the shape of the dispersion curve is not significantly modified by film composition. However, a great dislocation of the dispersion curves values is observed, around 0.12 from PMMA to PC at wavelength $633 \mathrm{~nm}$. By comparison, when the temperature is modified, the curve shapes remain almost unchanged, and the dislocation observed is less significant than that caused by composition change, as shown in Fig. 2(b) for the PC 40 wt \% film.

An interesting result is observed when the physical thickness and refractive index for a single wavelength are plotted versus temperature, as shown in Fig. 3 for the PC 80 wt $\%$ film. In all samples measured, behavior of physical thickness and refractive index was linear in the temperature range between 25 and $85^{\circ} \mathrm{C}$.

This behavior is expected, since no phase transitions are 


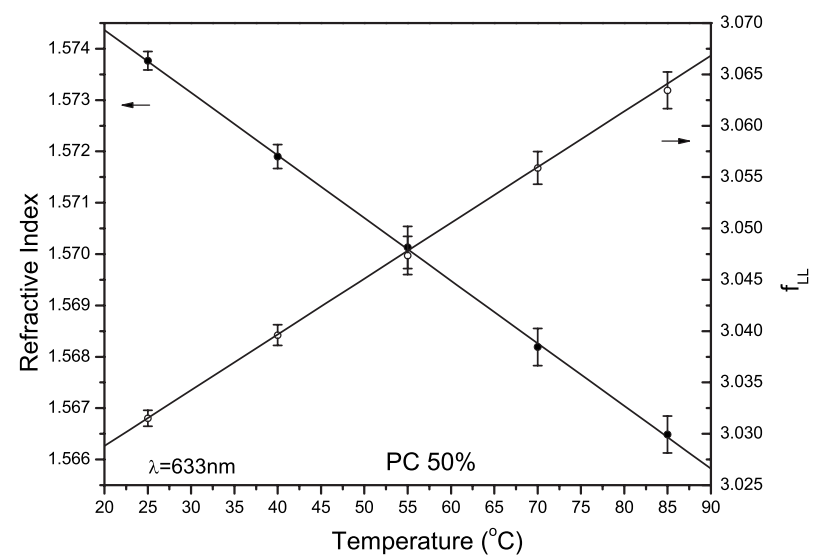

Fig. 4 Refractive index and $f_{L L}$ with standard deviation versus temperature for a PC 50 wt.\% film.

observed in this temperature interval. Therefore, it is possible to write the Lorentz-Lorenz factor $\left(f_{L L}\right)$ as a linear function of temperature:

$f_{L L}=\frac{n^{2}+2}{n^{2}-1}=a T+b$,

where $a$ and $b$ are constants.

The calculated $f_{L L}$ and refractive index values $(\lambda$ $=633 \mathrm{~nm})$ for the PC $50 \mathrm{wt} \%$ film at different temperatures are shown in Fig. 4.

Furthermore, since $\mathrm{aT} \ll b$ in this temperature interval, from Eqs (1) and (6), the volumetric expansion coefficient can be obtained from:

$\beta \cong \frac{a}{b}$

For this result, in the application of Eq. (1) to polymers, for which the contribution of the thermal expansion to refractive index variation is much higher than that of the electrical polarizability, i.e., $\Phi \ll \beta, \Phi$ was neglected.

Table 2 Film physical thicknesses, refractive indices, thermo-optic coefficients, and thermal expansion coefficients at $\lambda=633 \mathrm{~nm}$ and $25^{\circ} \mathrm{C}$ of several polymer combinations.

\begin{tabular}{lcccc}
\hline \hline \multicolumn{1}{c}{ Sample } & $\begin{array}{c}h \\
\left( \pm 5 \times 10^{-4}\right) \\
{[\mu \mathrm{m}]}\end{array}$ & $\begin{array}{c}n \\
\left( \pm 4 \times 10^{-4}\right) \\
\left(25^{\circ} \mathrm{C}\right)\end{array}$ & $\begin{array}{c}\text { TOC } \\
\left(\times 10^{-4}\right) \\
{\left[\mathrm{K}^{-1}\right]}\end{array}$ & $\begin{array}{c}\beta \\
\left(\times 10^{-4}\right) \\
{\left[\mathrm{K}^{-1}\right]}\end{array}$ \\
\hline PC & 0.4167 & 1.6118 & -1.72 & 2.43 \\
PC 80 wt \% & 0.6601 & 1.6031 & -1.47 & 1.99 \\
PC 50 wt \% & 0.3909 & 1.5738 & -1.11 & 1.77 \\
PC 40 wt \% & 0.3653 & 1.5508 & -1.25 & 2.02 \\
PC 20 wt \% & 0.4313 & 1.5239 & -1.31 & 2.18 \\
PMMA & 0.4954 & 1.4916 & -1.41 & 2.48 \\
\hline \hline
\end{tabular}

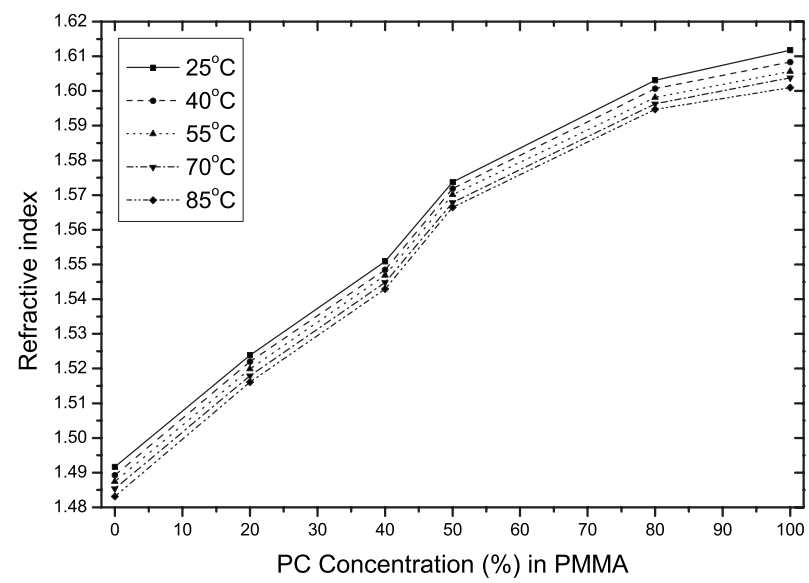

(a)

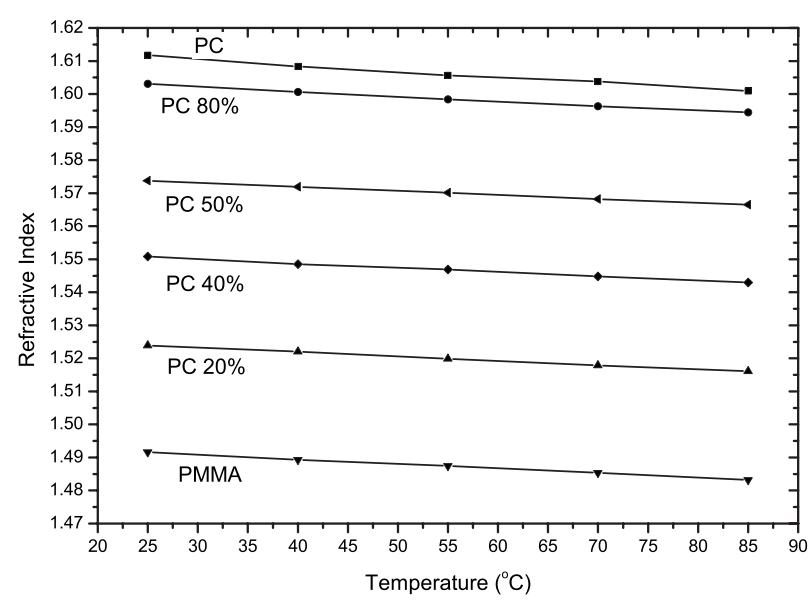

(b)

Fig. 5 (a) Refractive index isothermal curves as functions of PC concentration, and (b) refractive index variation as function of temperature for PC/PMMA and pure polymers (both at $\lambda=633 \mathrm{~nm}$ ).

Taking the slope of $f_{L L}$ curves and using Eqs. (6) and (7), the expansion coefficients from PC, PMMA, and PC/ PMMA films are calculated. Table 2 shows the values obtained for $\beta$, as well as the refractive index values, film physical thicknesses, and TOCs $\left(\lambda=633 \mathrm{~nm}\right.$ and $\left.25^{\circ} \mathrm{C}\right)$.

Last, in Fig. 5, refractive index dependences on polymer film composition and on temperature are show.

Figures 2 and 5 allow observation that refractive index values can be the tuned by adjusting film composition, temperature, or both. This is relevant for applications that require fine refractive index control. Furthermore, since TOC values associated with the slopes of curves shown in Fig. $5(\mathrm{~b})$, as well as the shape of the isothermal dispersion curves in Fig. 5(a), remain almost unchanged with variation of film composition, its fine-tuning becomes much facilitated for a specific application.

\section{Conclusion}

In this paper, fabrication and optical characterization of $\mathrm{PC} /$ PMMA films were proposed, as polymeric thermo-optical active film materials, with the benefit of refractive index tunability. The films were fabricated by spin-coating on sili- 
con substrates under saturated solvent atmosphere, using rotation speeds that kept physical thicknesses between 300 and $600 \mathrm{~nm}$. In situ spectroscopic ellipsometry measurements were performed with a dedicated autocontrolled heater, during heating cycles and at several temperatures $\left(25,40,55,70\right.$, and $\left.80^{\circ} \mathrm{C}\right)$. In this range of temperatures, no phase transitions could be observed in the composites, as expected, and refractive index dispersion curves, as well as Lorentz-Lorenz factors, are linear functions of temperature.

For each PC/PMMA film composition $(20,40,50$, or 80 wt \%), resulting film physical thicknesses and Cauchy dispersion coefficients were presented that allow determination of refractive indices and thermo-optical coefficient (TOC) values under a variety of wavelength and temperature ranges. Since the shape of the isothermal dispersion curves and TOC values remain almost unchanged with film composition, even with a pronounced shift of up to 0.12 in refractive index, wide-range fine-tuning of refractive index variation becomes much facilitated for a specific application.

Therefore, transparent PC/PMMA polymer, with TOC values one order of magnitude higher than that of silica, seem to be a viable alternative to this traditional material for integrated TO on Si chip devices that operate within the range of this study, with additional control of refractive index and its variation in a wide temperature and spectral range.

\section{Acknowledgments}

We are grateful for support from Conselho Nacional de Desenvolvimento Científico e Tecnológico (CNPq), Coordenação de Aperfeiçoamento de Pessoal do Ensino Superior (CAPES), and Programa Nacional de PósDoutoramento/Coordenação de Aperfeiçoamento de Pessoal do Ensino Superior (PNPD/CAPES).

\section{References}

1. H. Nishihara, M. Haruna, and T. Suhara, Optical Integrated Circuits, McGraw-Hill Book Company, New York (1989).

2. M. Born and E. Wolf, Principles of Optics, 6th ed., Cambridge University Press, Cambridge, UK (1997).

3. L. Prod'homme, Phys. Chem. Glasses 4, 119-122 (1960).

4. J. M. Cariou, J. Dugas, L. Martin, and P. Michel, "Refractive-index variations with temperature of PMMA and polycarbonate," Appl. Opt. 25(3), 334-336 (1986).

5. M. B. J. Diemeer, "Polymeric thermo-optic space switches for optical communications," Opt. Mater. 9, 192-200 (1998).

6. E. S. Kang, T. H. Lee, and B. S. Bae, "Measurement of the thermooptic coefficients in sol-gel derived inorganic-organic hybrid materia films," Appl. Phys. Lett. 81(8), 1438-1440 (2002).

7. X. J. Wang, L. Xu, D. X. Li, L. Y. Liu, and W. C. Wang, "Thermooptic properties of sol-gel-fabricated organic-inorganic hybrid waveguides," J. Appl. Phys. 94(6), 4228-4230 (2003).

8. A. Moujoud, Z. Saddiki, T. Touam, and S. I. Najafi, "Measurement of the refractive-index variations with temperature of hybrid sol-gel glasses," Thin Solid Films 422(1-2), 161-165 (2002).

9. Z. Zhang, P. Zhao, P. Lin, and F. Sun, "Thermo-optic coefficients of polymers for optical waveguide applications," Polymer 47, 48934896 (2006).

10. Y. Agari, A. Ueda, Y. Omura, and S. Nagai, "Thermal diffusivity and conductivity of PMMA/PC blends," Polymer 38(4), 801-807 (1997)

11. Y. Sun, M. V. D. Satyanarayan, N. T. Nguyen, and Y. C. Kwok, "Continuous flow polymerase chain reaction using a hybrid PMMA-PC microchip with improved heat tolerance," Sens. Actuators $B$ 130(2), 836-841 (2008).

12. N. Marin and B. D. Favis, "Co-continuous morphology development in partially miscible PMMA/PC blends," Polymer 43(17), 4723-4731 (2002)

13. K. Chen, X. Deng, X. Li, Z. Cao, Q. Shen, and H. Li, "Investigation of the influence of photobleaching process on the thermo-optic coefficient of disperse red 1/poly(methl methacrylate) film," Opt. Lasers Eng. 47(6), 708-711 (2009).

14. M. Courdille, M. Steers, and J. B. Thesten "Dispositif électronique, pour l'analyse et le calcul des coefficients de Fourier d'une fonction périodique et ellipsomètre comportant un tel dispositif (Electronic device, for analysis and calculation of Fourier coefficients of a periodical function and ellipsometer including such device)," \#80-20838, 1980, in French.

15. T. Watanabe, N. Ooba, Y. Hida, and M. Hikita, "Influence of humidity on refractive index of polymers for optical waveguide and its temperature dependence," Appl. Phys. Lett. 72(13), 1533-1535 (1998).

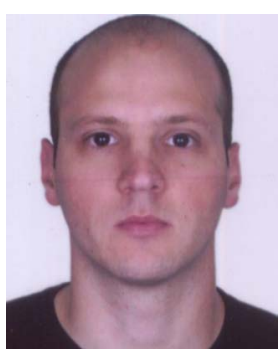

Paulo Azevedo Soave received a BSc in physics from Universidade Federal do Rio Grande do Sul (UFRGS), Porto Alegre, Brazil, in 2002. Presently, he is a PhD student in microeletronics at UFRGS, working on optical characterization of materials, optical films, and the development of sensors based on integrated optical waveguides.

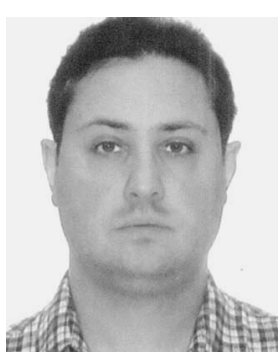

Ronaldo André Ferreira Dau received a BSc in physics from Universidade Federal do Rio Grande do Sul (UFRGS), Porto Alegre, Brazil, in 1999. Presently, he is a PhD student in microeletronics at UFRGS and works at UFRGS with nonlinear optical films.

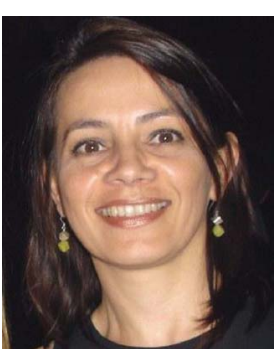

Márcia Regina Becker graduated in chemistry, with an MSc in materials engineering and $\mathrm{PhD}$ in material and metallurgical engineering from Universidade Federal do Rio Grande do Sul (UFRGS), in 2007. She has experience in synthesis and chemical analysis and is focusing on polymers, particularly on polyolefin blends and synthesis of polystyrene, polymethacrylate, and dyes, as well as preparation of thin polymer films for linear optics.

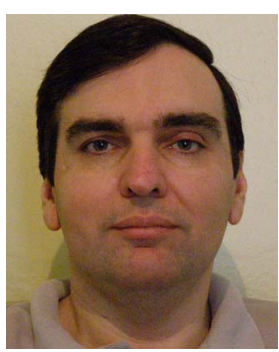

Marcelo Barbalho Pereira received a PhD in material sciences from Universidade Federal do Rio Grande do Sul (UFRGS) in 2003 and was postdoctoral fellow at the University of Louisville, Kentucky in 2006. Presently, he is a research associate at UFRGS, working on the optical characterization of materials and optical films and on the development of biological sensors based on integrated optical waveguides. 


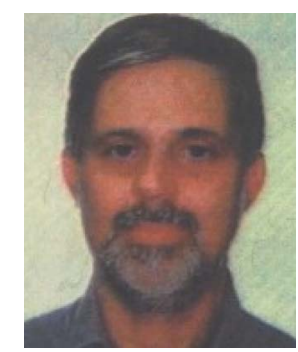

Flavio Horowitz received a PhD in optical sciences from the University of Arizona in 1983, and did postdoctoral work in the Optical and Semiconductor Devices Section, Imperial College, UK, in 1993. Presently, he is a professor of Physics at UFRGS in Porto Alegre and a Conselho Nacional de Desenvolvimento Científico e Tecnológico (CNPq) research leader of the Laser and Film Optics Group. His research activities include seminal contributions in the areas of structure-induced birefringence in thin films, optical properties of materials, and process interferometric monitoring, with application to the first birefringent film retarder at normal light incidence, a tunable visibility device for Smartt Interferometry, pioneer development of optopinography and optical monitoring of dip coating, innovative methods for noncontact laser viscometry (patented), poling optical polarimetry, and direct measurement of the near-surface refractive index in inhomogeneous films, also in real time (patented). His present interests include monitored manufacturing of optical coatings, nanocomposite films, superhidrofobicity, and characterization of optical materials with regard to optical devices. 